\title{
Menstruation, Mental Health and Stigma
}

\author{
Chitrita Sengupta Chaki ${ }^{1}$, Avinash De Sousa ${ }^{2}$ \\ ${ }^{1}$ Psychologist, Private Practice, Kolkata. \\ ${ }^{2}$ Consultant Psychiatrist and Founder Trustee, Desousa Foundation, Mumbai. \\ Corresponding author - Avinash De Sousa \\ E-mail-avinashdes888@gmail.com
}

\begin{abstract}
What is Menstruation
Menstruation is the periodic discharge of blood and tissue from the uterus, from puberty until menopause. It is a necessary biological function experienced by half of the population. It is the same as other biological functions such as sleeping, breathing, urinating and so on. Yet it is less spoken about and has its share of stigma, shame and taboo that has been present across the years and also has been understudied in Indian culture in many aspects.
\end{abstract}

\section{Menstruation: Stigma and Taboos}

It is estimated that at present, roughly 800 million girls and women aged between 13-40 years of age are menstruating every month. Despite women living almost 40 years of their lives with menstruation, it is dealt with shame, embarrassment, secrecy, stigma and of course taboos. Menstruation stigma and taboos are present in almost every society in varying degrees, here are a few places where menstruating women and girls endure unthinkable oppression and discrimination. The stigma is seen in most nations in Asia with varying distributions across nations and cultures.

\section{India}

In a country like India, our longstanding history of superstitions, taboos and stigma associated with menstruation continue to manifest in complex and subtle ways. A menstruating woman is often equated with dirty; impure; unclean leading to feelings of shame and fear. As soon as a girl reaches puberty, she is taught not to talk about her puberty openly, especially with boys or men. If she needs a pad, she should ask her mother or other women in a hushed tone so that nobody can hear it. Menstruation pads are always hidden undercover. Traditionally in India, women were prohibited from full participation in public and family life, participating or performing religious activities, touching certain food, performing domestic chores, staying in the same room with her husband. Basically, women were forced to remain isolated during menstruation as she is considered dirty, impure and clean. These customs are still practised at varying degrees in different parts of the country. Many people believe that if lady who is in her menstrual cycle touches pickle it shall go bad and if anyone cooks the food would go bad. Women for years have suffered in silence due to these beliefs and continue to do so.

The strong taboo associated with menstruation also makes people feel period is an uncomfortable and embarrassing and even dangerous topic, leading to the use of slang and code words to refer to menstruation. The scarcity of affordable menstruation hygiene products makes periods even more of a burden and health risk in India. In fact, almost 88percent of women in rural India still rely on clothes, rags, hay, ash, and even leaves to manage their periods. When their menstruation begins for the first time, over 23 per cent of girls in India drop out of school. Young girls remain absent on an average of five days of school per month because of their periods. Women's education can have a major impact on economic growth, which means the menstruation taboo can affect the prosperity of a country. Th is becomes even more difficult when we look at special populations like those with developmental disabilities and the menstrual cycle. 


\section{Nepal}

Women in Nepal face one of the greatest struggles when they begin getting their period as the menstruation taboos are associated with cultural and religious beliefs. Nepal's primary religion is Hinduism, which teaches that menstruating women are impure and polluted. This religious doctrine has led to the practice of chhaupadi for a large portion of western Nepal. Chhaupadi is a word that refers to a custom that requires women to be confined to a menstruation hut during their period. Chhaupadi poses a sanitary and safety threat. It is reported that women have even died in menstruation huts from smoke inhalation during fires, attacks from wild animals, and serious illnesses like dehydration. Women who observe this practice often spend their menstruation days in a cowshed that doubles as a menstruation hut, which causes humiliation and emotional distress.

Besides Chhaupadi, there are other prejudices against women related to their periods. Women are not allowed to have physical contact with their spouse or male relatives, can't enter their kitchens, in addition to being prohibited from going to the temple during their periods. These discriminatory practices are deeply ingrained in religious and cultural beliefs and are difficult to fight against.

\section{Indonesia}

Like India and Nepal, Indonesia shares similar kinds of taboos related to menstruation. Unlike India, menstruating women at workplaces in Indonesia are eligible to get leaves but the rural population of Indonesia is not lucky. Here the women are still viewed as dirty, they are prohibited to be touched by their husband as well as other members of the family and here also women perceive menstruation as embarrassing. In Indonesia, tampons are rarely available as it is believed that tampons lose the virginity of girls.

\section{Africa}

A study by UNICEF has pointed out that half of Africa's female population are deprived of basic menstruation hygiene, use of menstruation products and safety. The girls are deprived and discouraged by their mothers to use sanitary pads during their menstruation. Poverty, lack of access to menstruation hygiene, lack of education, superstition and stigma surrounding menstruation are some of the major barriers faced by girls and women in different African countries.

Most of the girls and women have very little or no access to sanitary tools or products, adequate and hygienic toilet facilities and proper menstrual hygiene mostly in rural areas worldwide making a women's life even more incredibly difficult to handle and live peacefully.

\section{Menstruation And Mental Health Issues - A Tangled Story}

Menstruation is not a new health condition but it has existed for ages and centuries over the world but it has been overlooked and ignored owing to our preoccupation associated with it. Moreover, in recent times though the physical attributes like stomach pain, cramps etc has been discussed but the menstruation and mental health - the silent connection. Mental health issues associated with menstruation have been totally ignored and overlooked again due to the prevailing stigma and taboo related to mental illness along with menstruation. Yet for many girls and young women around the world, the shame, stigma and pain attached to menstruation have put their mental health at risk.

\section{Factors affecting mental health during menstruation}

There are several factors that can affect the mental health of women during menstruation like genetic predispositions plays a vital role in the physical aspect of menstruation such as pain and flow; it also has an impact on the onset of menstruation and menopause. The perception and outlook towards menstruation are also impacted as the genes impact the personality. Hormones play an obvious role in the menstruation cycle. As the hormones fluctuate, women's feelings also get fluctuated like a swing as in the middle of the cycle women has a general feeling of wellbeing but as time progresses and with the onset of menstruation, the feeling of anxiety, irritability and low mood progresses. The fluctuations in hormones lead to disruption of brain chemicals called neurotransmitters, the most common of them during menstruation are serotonin and dopamine. Serotonin regulates mood, anxiety and emotion, Dopamine 
plays a role in how we feel pleasure and focus on things. Low levels of these two hormones result in not just food cravings but also unhappiness, anxiety and overall irritability. Mood alterations or commonly mood changes during menstruation are so subtle that they are not even cared for. The changing levels of hormones in the menstrual cycle are responsible for the emotional ride but sometimes the severity of mental conditions can be alarming and they may reflect a mental disorder.

Social factors also contribute to a greater extent in mental as well as physical well-being. Conditions such as financial issues, religious and cultural values and family support also impact the mental health of women during menstruation. This becomes a double whammy as in most societies menstruation and mental illness both are stigmatized leading to a life full of emotional turbulence. Women are often slaves to their hormones and social system, which increases during menstruation as they lack support from partners, parents and society as a whole.

\section{Premenstrual Syndrome and Premenstrual Dysmorphic Disorder (PMDD)}

The two most powerful outcomes of menstruation leading to disturbances in Mental Health are Premenstrual Syndrome (PMS) and Premenstrual Dysmorphic Disorder (PMDD). PMS and PMDD are the main disorders linked to menstruation. While PMS involves mild symptoms and is more prevalent, PMDD is more severe and is noted in 3-7 per cent of women. Symptoms of PMDD are altered mood, behavioural and physical symptoms. The diagnostic criteria for PMDD include accumulation of symptoms but the most important criterion is the duration in which the symptoms are noted. PMDD symptoms are present in the final week before the onset of menstruation and they start to improve after the onset. Symptoms are minimal or absent in the week after menstruation is over. Some of the major symptoms of PMDD include mood swings, tearfulness and increased sensitivity to rejection; marked irritability or increased interpersonal conflicts; increased anxiety or tension; lethargy; apathy; marked change in appetite; hypersomnia or insomnia, etc.

Both PMS and PMDD should be dealt with and treated with medical supervision and the treatment should be under the guidance of a gynaecologist, Psychiatrist and Psychologist as well. While medications can reduce your symptoms, consultation with a psychologist will help a woman to handle and deal with her emotions, mood, interpersonal conflicts etc in a more rational way, thus a comprehensive treatment is adopted.

While 100 per cent of the world population has mental health - good or bad, and half of this population menstruates, it is not surprising that the link between mental health and menstruation is of utmost importance. It is the priority of the time to bridge the issues of menstruation and mental health. Efforts need to be made to destigmatize mental health taboos and menstruation stigma as well as taboos to save women from greater risk of poor physical as well as mental health and menstruation struggles- a war for both the gender to win and not one to lose.

\section{Conclusions}

Menstruation related issues need to be addressed in our country and many Asian nations. There is a need for public education and awareness about the same. There is enough literature to suggest that girls and women in low-income countries face greater struggles. Putting an end to discriminatory social practices, educating and creating awareness among men and women equally will provide women with improvement in menstrual hygiene leading to better mental health and advancements in human rights in many countries around the globe. The hope is that education and awareness talk will help children of both genders. The aim must be to spread awareness and remove the stigma associated with mental health and menstruation and to help individuals irrespective of gender to embrace emotional wellness and menstruation struggles efficiently.

\section{REFERENCES}

1. Johnston-Robledo I, Chrisler JC. The menstrual mark: Menstruation as social stigma. Sex Roles 2013;68(1):9-18.

2. Chrisler JC. Teaching taboo topics: Menstruation, menopause, and the psychology of women. Psychol Women Quart 2013;37(1):128-32. 
3. Crawford M, Menger LM, Kaufman MR. 'This is a natural process': managing menstrual stigma in Nepal. Culture Health Sexuality 2014;16(4):426-39.

4. Wister JA, Stubbs ML, Shipman C. Mentioning menstruation: A stereotype threat that diminishes cognition?. Sex Roles 2013;68(1):19-31.

5. Chrisler JC, Marván ML, Gorman JA, Rossini M. Body appreciation and attitudes toward menstruation. Body Image 2015; 12:78-81.

6. Garg S, Anand T. Menstruation related myths in India: strategies for combating it. J Fam Med Prim Care 2015;4(2):184-9.

$\star * * * * * * * * * * * * * * * * * * * * * * * * * * * *$

Acknowledgements - Nil

Source of Funding - Nil

Conflict of Interest - Nil 